\title{
Depressive Symptoms Among Sarajevo University Students: Prevalence and Socio-Demographic Correlations
}

\author{
Amela Džubur ${ }^{1}$, Damir Abdulahović ${ }^{2}$, Amira Kurspahić-Mujčić ${ }^{1}$, Alen Džubur ${ }^{3}$, \\ Svjetlana Loga-Zec ${ }^{4}$, Venesa Škrijelj ${ }^{1}$
}

${ }^{1}$ Department of Public Health, Faculty of Medicine, University of Sarajevo, ${ }^{2}$ Institute for Public Health of Canton Sarajevo, ${ }^{3}$ Department of Cardiology, Clinical Center University of Sarajevo, ${ }^{4}$ Department of Pharmacology, Clinical Pharamcology and Toxicology, Faculty of Medicine, University of Sarajevo

\author{
Correspondence: \\ damir.abdulahovic@gmail.com \\ Tel.: + 38761674595 \\ Fax.: + 38733627889
}

Received: 26 June 2018

Accepted: 30 October 2018

Key words: Depressive Symptoms • Beck Scale - BDI Score - University Students.
Objectives. The aim of this research was to detect the presence of depressive symptoms among the student population at a Faculty of Medicine, as well to determine the correlation between the socio-demographic characteristics and students' lifestyle and depressive symptoms. Subjects and Methods. Of 800 students enrolled and asked to participate, 412 responded to the survey. The study included students from all 6 years of studies. The degree of depressive symptoms was measured by a 21-item revised form of the Beck Depression Inventory (BDI). We built bivariate logistic regression models to study whether age, gender, housing accommodation, year of medical training, and school success status (Grade Point Average - GPA) were associated with depressive symptoms. The results are reported as odds ratios (OR) with $95 \%$ confidence intervals (CI). Results. The study revealed that almost one third of students reported BDI $>16(30.1 \%)$. The present study did not find any association between BDI scores and study year or age difference, but we found that there was an association between housing accommodation and depressive symptoms. Students who lived with their parents had lower BDI scores than those who lived in a dormitory. The results of this study showed there is a negative correlation between physical activity and depressive symptoms in students, as well as that there is a positive correlation between depressive symptoms and substance abuse. Conclusion. Overall, our study confirms that the factors associated with an increase in medical students' depressive symptoms are housing accommodation, a lack of physical activity and substance abuse. Regarding failing a year of study at the medical school, as well as gender and age differences, we did not find any significant difference between students with higher compared to those with lower depressive symptoms.

\section{Introduction}

Depressive disorders are one of the most common mental disorders, with a lifetime prevalence of $16.2 \%$ and 12 -month prevalence of $6.6 \%$ in the general population (1). Depression affects people of all ages, from all walks of life, in all countries. It causes men- tal anguish and impacts people's ability to carry out even the simplest everyday tasks, with sometimes devastating consequences for relationships with family and friends, and the ability to earn a living. At worst, depression can lead to suicide, which is now the second leading cause of death among 1529 year-olds (2). 
It is known that females are more likely to suffer than males, given the complex interaction of females' biological, psychological and social-cultural vulnerability. There is a significant increase in the incidence of depressive symptoms during pregnancy and especially postpartum. Other risk factors include: a positive family history for depression, the existence of a physical illness that causes disability or pain, and other mental disorders, such as dementia. Depression is also increased by stress and poor socio-economic conditions of life (3).

However, depression can be prevented and treated. A better understanding of what depression is, and how it can be prevented and treated, will help reduce the stigma associated with the condition, and lead to more people seeking help (3). It is estimated that more than 450 million people suffer from mental disorders, and every fourth person may have some mental health problems in their lifetime. 350 million people (5\%) of the world's population suffer from depressive disorders (4). Depression will be the second greatest global burden by 2020, but also a leading health issue in developed countries. Treatment costs for depression by 2030 will increase so much that it will become a major problem for the financial stability of health care systems (4).

According to a WHO-led study (5), which calculated treatment costs and health outcomes in 36 low-, middle- and high-income countries for the 15 years from 20162030, low levels of recognition of and access to care for depression, and another common mental disorder, anxiety, will result in a global economic loss of a trillion US dollars every year. The losses are incurred by households, employers and governments. Households lose financially when people cannot work. Employers suffer when employees become less productive and are unable to work. Governments have to pay higher health and welfare costs.
In research published last year by the Journal of the American Medical Association (6), based on an international survey, $27 \%$ of medical students reported symptoms of depression. Another problem is that students training to care for the mental and physical health of others do not have time to tend to their own health (6). In 2016, in the region of the Sarajevo Canton, 7.28 persons per 1,000 inhabitants (7) had some kind of mental disorder, including depression, but there are no records that include the representation of mental health disorders in the student population for the Federation of Bosnia and Herzegovina (BH) or Sarajevo Canton (7).

Recently there have been a number of studies on the prevalence of depressive symptoms in university students worldwide (8-11). A study about depressiveness among Chinese university students showed that the prevalence of depressive symptoms was $11.7 \%$, and $4.0 \%$ of the sample was experiencing a Major Depressive Disorder (1). Bayram \& Bilgel reported that depressive symptoms of moderate severity or above were found in $27.1 \%$ of Turkish university students (9), while Bostanci reported out of all university students in Denizli, 26.2\% had a Beck Depression Inventory (BDI) score of 17 or higher, and also that no differences in depressive symptoms were observed between male and female students (10). Among other things, this study showed that senior students had higher BDI scores compared with freshmen (11). Moreover, students with learning disabilities, as well as those who were dissatisfied with their major study course, the quality of the educational system, their living arrangements, their social life and the university facilities available, were more likely to report clinical depressive symptoms (11).

The aim of this research was to detect the presence of depression and depressive symptoms among the student population at 
the Faculty of Medicine, University of Sarajevo, as well to determine the correlations between the students' socio-demographic characteristics and lifestyle and depressive symptoms, and compare the results with major studies conducted around the world.

\section{Methods}

\section{Study Population}

The Faculty of Medicine is an organizational unit of the University of Sarajevo. In total, there were 800 students enrolled in regular classes in the academic year 2016/2017. Students attending medical studies in English were not included in this research due to language restrictions and the possibility of the influence of the different socio-demographic characteristics of the sample (the countries from which they come from, the amount of income, their lifestyle and customs). The total number of students who responded to the survey was 412 . The study included students from all 6 years of studies.

\section{The Questionnaire}

The research was designed as a cross-sectional study and it was conducted by means of a questionnaire consisting of two parts: the first part examined the sociological characteristics and student's lifestyle, and the second part examined depressiveness in students, using Beck's scale, adapted to this research and translated into the official languages of Bosnia and Herzegovina (12).

The degree of depressive symptoms was measured by a 21 -item revised form of the Beck Depression Inventory (BDI) (12). The BDI statements were ranked from 0 to 3 , with 0 representing the least serious and 3 the most serious symptoms. The questionnaire contained 18 questions in the first part and 21 groups of items divided into 8 thematic units in the second part. Each state- ment in this inventory had a possible score range of 0 to 3, with the total score being 63 . A referral BDI score value of 0 to 4 is considered as normal, 5 to 13 represents borderline clinical depression, 14 to 20 moderate depression, and 21 to 63 severe depression (13). We used a BDI score cutoff of 16 to be able to compare it with other studies (10) and because a score of 17 or more is used as the conventional cutoff for clinical depression. After prior approval had been granted by Dean of the Faculty, the research was conducted from 23.3.2017 to 31.3.2017. The students filled out the questionnaires by themselves online. The socio-demographic variables analyzed were: age, gender, year of studies, mean grade point average (GPA), duration of studies, failing a year of studies, accommodation, physical activity - running, jogging or gym, time spent weekly on physical activity, time spent on computer/ laptop per week, having hobbies, visits to a psychologist/psychiatrist, use of psychoactive substances - light and heavy drugs in recent years.

\section{Statistical Analysis}

Logistic regression was used to assess the relationship between the socio-demographic variables and the symptoms of depression. A bivariate logistic model was calculated by taking each correlate at a time. We built bivariate logistic regression models to study whether age, sex, housing accommodation, year of medical training and study success status (grade point average - GPA) were associated with depressive symptoms. The results are reported as odds ratios (OR) with 95\% confidence intervals (CI). Betweengroup comparisons for categorical and binary data were computed by means of the chi square test and $\mathrm{P} \leq 0.05$ was considered to be statistically significant. The SPSS statistical package (SPSS Inc., Chicago, IL, USA) was used for data analysis. 


\section{Results}

The total number of respondents was 412 students, of which 115 (27.9\%) were men and 297 (72.1\%) were women. The mean ( \pm standard deviation) age of the participants was $21.6 \pm 2.8$ (range 17-41 years). Most of the respondents were $20-21$ years old (32.8\%), then 18 - 19 years old (25.2\%), 24 and older (22.1\%) and $19.9 \%$ were $22-23$ years old. The largest number of the respondents were students in their $1^{\text {st }}$ year of medical studies, $34.0 \%$ of all students included $(n=140)$, followed by $21.6 \%$ respondents from the $2^{\text {nd }}$ year of medical studies $(n=89), 12.9 \%$ respondents $(n=53)$ from the $5^{\text {th }}$ year, $12.6 \%$ $(n=52)$ from the $3^{\text {rd }}$ year, $11.9 \%(n=49)$ from the $6^{\text {th }}$ year and $7.0 \%(n=29)$ respondents in their $4^{\text {th }}$ year of medical studies.

The majority of the respondents were within the referral BDI value range, 195 of them (47.3\%). Mild depressive symptoms were found in 93 of the respondents, which is $22.6 \%$, borderline clinical depressive symptoms were present at 40 respondents (9.7\%), moderate depressive symptoms in 65 cases $(15.8 \%)$, severe depressive symptoms in $15(3.6 \%)$ respondents, and, finally, 4 respondents had scores that showed severe depression symptoms, with scores above 47 (1.0\%).

The average $\mathrm{BDI}$ score was 21.63 (SD= $\pm 2.77)$ while $30.1 \%$ of students had BDI $>16(\mathrm{n}=124) \quad($ Table 1). The referral BDI value was found in 58 men (50.4\%) and 137 women (46.1\%). Mild depressive symptoms were found in 21 male respondents (18.3\%) and 72 female respondents $(24.2 \%)$. Borderline clinical depressive symptoms were found in 18 male students (15.7\%) and $22(7.4 \%)$ female students. Moderate depressive symptoms were found in 13 men $(11.3 \%)$ and 52 women (17.5\%), severe depressive symptoms in $4(3.5 \%)$ men and 11 women (3.7\%). Severe depressive symptoms with score above 47 were evaluated in 1 man
$(0.9 \%)$ and 3 women (1.0\%). Table 2 shows the results of bivariate logistic regression models for the association between students' BDI scores and different socio-demographic characteristics. According to the bivariate logistic model, the odds of having depressive symptoms are insignificantly higher in students group who have GPA less than 8.00 , have no hobby, as well as for students who live in their own apartment and spend more than 90 minutes on computer/laptop per week. The odds of having depressive symptoms were significantly higher in students, who live in a dormitory, do not undertake any physical activity, and who have used psychoactive substances or ever visited a psychologist/psychiatrist.

The distribution of the respondents in relation to gender (sex) and depressive symptoms was not statistically significant $\left(\chi^{2}(5.412)=9.494, \mathrm{P}=0.091\right) . \mathrm{BDI}>16$ varied between different age groups with a range from $28.8 \%$ (the lowest value) to $31.7 \%$ (the highest value) and distribution of the respondents in relation to gender (sex) and depressive symptoms was not statistically significant $(\mathrm{P}=0.979)$.

Students with less successful academic performance (mean GPA less than 8.00) had higher occurrence of depressive symptoms $(32.7 \%$ students in this group had BDI $>16$ ), compared to students with better school performance (mean GPA 8.00-10.00) with $28.2 \%$ of students with BDI $>16$ in this group, but there was a non-statistically significant difference in the occurrence of depressive symptoms between less and more successful students $(\mathrm{P}=0.323)$.

$29.7 \%$ of students had failed a year during their studies and had BDI $>16$, while $30.7 \%$ students that had not failed a year had BDI $>16$. There was no statistically significant difference in the occurrence of depressive symptoms between students who had failed and those who had not failed a year of studies. 
Table 1. Socio-Demographic Characteristics of Students in Relation to Depressive Symptoms

\begin{tabular}{|c|c|c|c|c|}
\hline \multirow{2}{*}{$\begin{array}{l}\text { Socio-demographic } \\
\text { characteristics }\end{array}$} & \multirow{2}{*}{$\begin{array}{l}\text { Percent of students with } \\
\text { BDI } \leq 16^{*} \\
\mathrm{~N}(\%)\end{array}$} & \multirow{2}{*}{$\begin{array}{l}\text { Percent of students with } \\
\text { BDI >16† } \\
\mathrm{N}(\%)\end{array}$} & \multicolumn{2}{|c|}{$\begin{array}{l}\text { Statistical } \\
\text { analysis }^{\ddagger}\end{array}$} \\
\hline & & & $x^{2}$ test & $\mathrm{P}$ \\
\hline \multicolumn{5}{|l|}{ Sex } \\
\hline Both sexes & $288(69.9)$ & $124(30.1)$ & \multirow{3}{*}{0.111} & \multirow{3}{*}{0.740} \\
\hline Male & $79(68.7)$ & $36(31.3)$ & & \\
\hline Female & $209(70.4)$ & $88(29.6)$ & & \\
\hline \multicolumn{5}{|l|}{ Age group (year) } \\
\hline 18-19 & $74(71.2)$ & $30(28.8)$ & \multirow{4}{*}{0.191} & \multirow{4}{*}{0.979} \\
\hline $20-21$ & $94(69.6)$ & $41(30.4)$ & & \\
\hline $22-23$ & $56(68.3)$ & $26(31.7)$ & & \\
\hline 24 and more & $64(70.3)$ & $27(29.7)$ & & \\
\hline \multicolumn{5}{|l|}{ Year of studies } \\
\hline $1^{\text {st }}$ & $100(71.4)$ & $40(28.6)$ & \multirow{6}{*}{4.159} & \multirow{6}{*}{0.527} \\
\hline $2^{\text {nd }}$ & $58(65.2)$ & $31(34.8)$ & & \\
\hline $3^{\text {rd }}$ & $38(73.1)$ & $14(26.9)$ & & \\
\hline $4^{\text {th }}$ & $24(82.8)$ & $5(17.2)$ & & \\
\hline $5^{\text {th }}$ & $35(66.0)$ & $18(34.0)$ & & \\
\hline $6^{\text {th }}$ & $33(67.3)$ & $16(32.7)$ & & \\
\hline \multicolumn{5}{|l|}{ Mean GPA } \\
\hline $6.00-6.99$ & $1(100.0)$ & $0(0.0)$ & \multirow{6}{*}{5.032} & \multirow{6}{*}{0.412} \\
\hline 7.00-7.49 & $30(68.2)$ & $14(31.8)$ & & \\
\hline 7.50-7.99 & $84(66.7)$ & $42(33.3)$ & & \\
\hline 8.00-8.49 & $113(68.1)$ & $53(31.9)$ & & \\
\hline $8.50-8.99$ & $45(80.4)$ & 11 (19.6) & & \\
\hline $9.00-10.00$ & $15(78.9)$ & $4(21.1)$ & & \\
\hline \multicolumn{5}{|l|}{ Duration of studies } \\
\hline 1 year & 76 (71.7) & $30(28.3)$ & \multirow{7}{*}{9.395} & \multirow{7}{*}{0.153} \\
\hline 2 years & $42(61.8)$ & $26(38.2)$ & & \\
\hline 3 years & $41(68.3)$ & $19(31.7)$ & & \\
\hline 4 years & $21(80.8)$ & $5(19.2)$ & & \\
\hline 5 years & $28(59.6)$ & $19(40.4)$ & & \\
\hline 6 years & $46(80.7)$ & $11(19.3)$ & & \\
\hline More than 6 years & $34(70.8)$ & $14(29.2)$ & & \\
\hline \multicolumn{5}{|l|}{ Failing a year of studies } \\
\hline Yes & $114(70.8)$ & $47(29.2)$ & \multirow{2}{*}{0.103} & \multirow{2}{*}{0.749} \\
\hline No & $174(69.3)$ & $77(30.7)$ & & \\
\hline \multicolumn{5}{|l|}{ Accommodation } \\
\hline With his/ her parents & $101(67.3)$ & $49(32.7)$ & \multirow{4}{*}{2.840} & \multirow{4}{*}{0.417} \\
\hline Rented apartment & $106(67.1)$ & $52(32.9)$ & & \\
\hline Their own apartment & $18(64.3)$ & $10(35.7)$ & & \\
\hline Dormitory & $46(60.5)$ & $30(39.5)$ & & \\
\hline
\end{tabular}


Table 1. Socio-Demographic Characteristics of Students in Relation to Depressive Symptoms

\begin{tabular}{|c|c|c|c|c|}
\hline \multirow{2}{*}{$\begin{array}{l}\text { Socio-demographic } \\
\text { characteristics }\end{array}$} & \multirow{2}{*}{$\begin{array}{l}\text { Percent of students with } \\
\text { BDI } \leq 16^{*} \\
\mathrm{~N}(\%)\end{array}$} & \multirow{2}{*}{$\begin{array}{l}\text { Percent of students with } \\
\text { BDI >16† } \\
\mathrm{N}(\%)\end{array}$} & \multicolumn{2}{|c|}{$\begin{array}{l}\text { Statistical } \\
\text { analysis }^{\ddagger}\end{array}$} \\
\hline & & & $\mathrm{X}^{2}$ test & $\mathrm{P}$ \\
\hline \multicolumn{5}{|l|}{ Physical activity ${ }^{\S}$} \\
\hline Yes & $185(73.7)$ & $66(26.3)$ & \multirow{2}{*}{4.414} & \multirow{2}{*}{0.036} \\
\hline No & $103(64.0)$ & $58(36.0)$ & & \\
\hline \multicolumn{5}{|c|}{ Time spent weekly on physical activity } \\
\hline Less than $30 \mathrm{~min}$ & $135(64.9)$ & $73(35.1)$ & \multirow{4}{*}{5.214} & \multirow{4}{*}{0.157} \\
\hline $30-60 \mathrm{~min}$ & $66(76.7)$ & $20(23.3)$ & & \\
\hline $60-90 \mathrm{~min}$ & $30(73.2)$ & $11(26.8)$ & & \\
\hline More than $90 \mathrm{~min}$ & $38(51.9)$ & $29(26.0)$ & & \\
\hline \multicolumn{5}{|c|}{ Time spent on computer/laptop per week } \\
\hline Less than 90 minutes & $128(72.7)$ & $48(27.3)$ & \multirow{2}{*}{1.165} & \multirow{2}{*}{0.280} \\
\hline More than 90 minutes & $160(67.8)$ & $76(32.2)$ & & \\
\hline \multicolumn{5}{|l|}{ Do you have hobby } \\
\hline Yes & $188(72.0)$ & $73(28.0)$ & \multirow{2}{*}{1.532} & \multirow{2}{*}{0.216} \\
\hline No & $100(66.2)$ & $51(33.8)$ & & \\
\hline \multicolumn{5}{|c|}{ Have you ever visited a psychologist/psychiatrist } \\
\hline Yes & $39(59.1)$ & $27(40.9)$ & \multirow{2}{*}{4.367} & \multirow{2}{*}{0.037} \\
\hline No & $249(72.0)$ & $97(28.0)$ & & \\
\hline \multicolumn{5}{|c|}{ Do you use any psychoactive substances" } \\
\hline Yes & $20(51.3)$ & $19(48.7)$ & \multirow{2}{*}{7.100} & \multirow{2}{*}{0.008} \\
\hline No & $268(71.8)$ & $105(28.2)$ & & \\
\hline
\end{tabular}

"Beck depression inventory; ${ }^{+} \mathrm{BDI}$ scores were dichotomized using 17 as the cut-off point. This column shows the percentage of the people

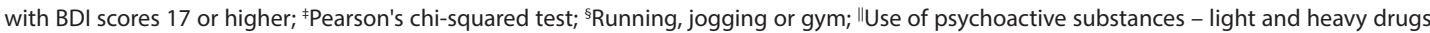
in recent years.

According to the bivariate logistic model, the odds of having depressive symptoms were higher in students who lived in a dormitory compared to ones who lived with their parents.

Assessing activity and depressive symptoms, $26.3 \%$ active students had BDI $>16$ in the active group, and $36.0 \%$ students with no activity and BDI $>16$ in the inactive group. There was a statistically significant difference in the occurrence of depressive symptoms between active and inactive students $(\mathrm{P}=0.036)$. The prevalence of depressive symptoms was not significantly different between those who spent more than 90 minutes on a laptop per week, and those who spent less time $(\mathrm{P}=0.280)$.
63.3\% students answered positively regarding having a hobby while $36.7 \%$ had no hobbies. $28.0 \%$ students with hobbies and $33.8 \%$ students with no hobbies had BDI $>16$.

Comparing students who had visited a psychologist/psychiatrist (16.0\%) and those who had not done so at any time in their lives $(84.0 \%)$, the students from the first group presented with a higher prevalence of depressive symptoms than students who had never visited a psychologist/psychiatrist (BDI $>1640.9 \%$ vs. $28.0 \%, \mathrm{P}=0.037$, respectively). A small number of students admitted using psychoactive substances $(9.5 \%$ vs. $90.5 \%)$. A statistically significant difference was noted in the prevalence of depressive symptoms with regard to substance abuse. In the group of students with substance 
Table 2. Description of the Sample and Association of Depressive Symptoms with Socio-Demographic Characteristics in University Students

\begin{tabular}{|c|c|c|}
\hline \multirow{2}{*}{ Socio-demographic characteristics } & \multicolumn{2}{|l|}{ Bivariate model $^{*}$} \\
\hline & $\mathrm{OR}^{\dagger}$ & $95 \% \mathrm{Cl}^{\ddagger}$ \\
\hline \multicolumn{3}{|l|}{ Sex } \\
\hline Female & Reference group & - \\
\hline Male & 0.92 & $0.58-1.47$ \\
\hline \multicolumn{3}{|l|}{ Age group (year) } \\
\hline $18-19$ & Reference group & - \\
\hline $20-21$ & 0.93 & $0.53-1.63$ \\
\hline $22-23$ & 0.87 & $0.47-1.64$ \\
\hline 24 and more & 0.96 & $0.52-1.78$ \\
\hline \multicolumn{3}{|l|}{ Year of studies } \\
\hline $1^{\text {st }}-3^{\text {rd }}$ & Reference group & - \\
\hline $4^{\text {th }}-6^{\text {th }}$ & 1.04 & $0.66-1.63$ \\
\hline \multicolumn{3}{|l|}{ Mean GPA ${ }^{\S}$} \\
\hline 8.00 and more & Reference group & - \\
\hline Less than 8.00 & 1.24 & $0.81-1.90$ \\
\hline \multicolumn{3}{|l|}{ Failed a year of studies } \\
\hline Yes & Reference group & - \\
\hline No & 0.93 & $0.60-1.44$ \\
\hline \multicolumn{3}{|l|}{ Accommodation } \\
\hline With his/ her parents & Reference group & - \\
\hline Rented apartment & 1.05 & $0.65-1.69$ \\
\hline Their own apartment & 1.21 & $0.50-1.69$ \\
\hline Dormitory & 1.68 & $0.89-3.19$ \\
\hline \multicolumn{3}{|l|}{ Physical activity\| } \\
\hline Yes & Reference group & - \\
\hline No & 1.58 & $1.03-2.42$ \\
\hline \multicolumn{3}{|l|}{ Time spent weekly on physical activity } \\
\hline More than $60 \mathrm{~min}$ & Reference group & \\
\hline Less than $60 \mathrm{~min}$ & 1.30 & $0.81-2.09$ \\
\hline \multicolumn{3}{|c|}{ Time spent on computer/laptop per week } \\
\hline More than 90 minutes & Reference group & - \\
\hline Less than 90 minutes & 0.79 & $0.51-1.21$ \\
\hline \multicolumn{3}{|l|}{ Do you have hobby } \\
\hline Yes & Reference & - \\
\hline No & 1.31 & $0.85-2.02$ \\
\hline \multicolumn{3}{|c|}{ Have you ever visited a psychologist/psychiatrist } \\
\hline No & Reference group & \\
\hline Yes & 1.78 & $1.03-3.06$ \\
\hline \multicolumn{3}{|c|}{ Do you use any psychoactive substances" } \\
\hline No & Reference group & - \\
\hline Yes & 2.43 & $1.24-4.73$ \\
\hline
\end{tabular}

'The bivariate model comes from a backward stepwise logistic regression analysis; ${ }^{\dagger}$ Odds ratio; ${ }^{\ddagger}$ Confidence interval; ${ }^{5}$ Grade Point Average; "Running, jogging or gym; "Use of psychoactive substances - light and heavy drugs in recent year. 
abuse, $48.7 \%$ had BDI $<16$ while $28.2 \%$ students who did not use psychoactive substances had BDI <16 $(\mathrm{P}=0.008)$. According to the bivariate logistic model, the odds of having depressive symptoms were significantly higher in students who had visited a psychologist/psychiatrist (OR of depressive symptoms was $1.78,95 \% \mathrm{CI}, 1.03-3.06)$ and who had used psychoactive substances in recent years (OR of depressive symptoms was $2.43,95 \%$ CI, 1.24-4.73).

\section{Discussion}

The primary scope of the present study was to provide an estimate of the prevalence of depressive symptoms among university students at the Faculty of Medicine of the University of Sarajevo. Furthermore, the study explored depressive symptoms and their association with individual, academic and social characteristics. The study revealed that almost one third of students reported BDI $>16(30.1 \%)$ which is more that measured in other countries, such as Turkey (26.2\%) (2) and China (22.91\%) (1). We did not perceive any gender differences in depressive symptoms in our study. We hypothesize that this situation originates from the fact that female students at our university, and in general, are strongly opinionated, more self-assured, and are aware of having equal or more rights compared with the situation in the past. Similar observations were made in other studies (10). Contrary to our results, significantly more depressive symptoms were found in female students than in male students in two different studies $(11,14)$.

The present study did not find any association between BDI scores and study year. Dogan et al. also found no difference in relation to study year in terms of depressive symptoms, as there was no positive correlation between study year and increased average BDI scores (14). On the other hand, several studies did find an association between
BDI scores and study year $(8,10)$ with freshmen being less depressed. In the present study, we found that there was no significant association between academic success and depressive symptoms. However, we must add that students who were more successful and had better mean GPA, had lower BDI scores than those who were less successful. The odds of having depressive symptoms were significantly higher in students who lived in a dormitory compared to students who lived with their parents. We hypothesize that this is a result of having security and support while living with parents rather than in dormitory with other students.

The results of this study showed there is a negative relationship between physical activity and depressive symptoms in students. There are several possible mechanisms of how physical activity can influence depressive symptoms. Exercising may have a physiological effect on depressiveness with an increased release of $\beta$-endorphins and neurotransmitters such as serotonin and dopamine (15). Another presumed explanation is that exercise decreases psychological stress and acts as a shield against traumatic incidents. In addition, participation in regular exercise programs may express a sense of prowess and improved self-esteem. Participation in exercise programs or exercise groups can also provide social connections and increase the participants' social skills. Furthermore, students who participate in after-class physical activities in the "natural" environment, recreational areas, parks, and playgrounds, may improve their mental health (16). Other studies $(17,18)$ also identified an inverse relationship between physical activity, including participation in sports, and depressive symptoms among students, which is in accordance with the present study.

It was also found that there is a positive relationship between depressive symptoms and substance abuse. Alcohol and 
some other substances actually increase the stress response by stimulating production of stress hormones. Alcohol directly activates the hypothalamus-pituitary-adrenal axis to produce excess cortisol. Substance abuse produces physiological stress and the body's responses to this kind of stress are similar to its responses to other stressors. Nevertheless, some individuals abuse substances to alleviate stress, wrongly thinking that it will help them deal with stress.

In the comparison of students who have visited a psychologist/psychiatrist and those who never have in their lifetime, it was found that students from the first group showed a higher prevalence of depressive symptoms than students who had never visited a psychologist/psychiatrist. This could suggest that medical students with more severe depressive symptoms either have better access to psychological support or/and perceive it better and seek help.

\section{Limitations of the Study}

There were several limitations to the present study. The first limitation is the potential for sampling bias, as the sample in the study was randomly selected from only the Faculty of Medicine. It is hard to generalize our findings to all Sarajevo University students. However, we had a moderate sample size and used Beck's scale to diagnose depressive symptoms. The second point is that we only surveyed the depressiveness distribution in university students and did not consider other psychological problems, such as anxiety. The end sample size is small, and further longitudinal, more accurate studies are needed in order to confirm this merely preliminary report. Another limitation of our study is that we did not consider family history of depressiveness and stressful events. A future study may be required to examine the factors related to genetic and/or other environment variables. Slightly more than $50 \%$ of the eligible population responded to the survey. Students who did not respond to the survey could be completely different to those who were included in the study and this could introduce substantial selection bias. Our data were collected crosssectionally and it is not possible to establish any temporal link between the individual socio-demographic characteristics, school performance and lifestyle and depressive symptoms. Therefore, it is possible that the link observed is reverse, i.e. it is possible that students who are more depressed use more psychoactive substances, and also that those who use psychoactive substances become more depressed. It is also possible that students who are depressed do less physical activity, but also that those who do less physical activity become more depressed. Cross-sectional design could be one of the limitations when interpreting associational results.

\section{Conclusion}

The prevalence of depressive symptoms in Sarajevo University students was relatively high throughout our study, reaching almost onethird (30.1\%). This indicates that a need for knowledge concerning depressive symptoms still exists and should be addressed by depressiveness-related health education programs. The factors associated with the increase in medical students' depressiveness were: housing accommodation, lack of physical activity and substance abuse. Regarding the years of study at the medical school, as well as gender and age differences, we did not find any significant difference between students. Access to psychological care and support is very important because students with mood problems are part of society and we have a moral and ethical responsibility to help them. 


\section{What is already known on this topic}

Depressive disorder is one of the most common mental disorders. Depression affects people of all ages, from all walks of life, in all countries. It is known that women are more likely to suffer than males, given the complex interaction of women's biological, psychological and social-cultural vulnerability. Depression is also increased by stress and poor socio-economic conditions in life.

\section{What this study adds}

The prevalence of depressiveness in Sarajevo University students was relatively high. The factors associated with the increase in medical students' depressiveness were: academic success, the lack of physical activity, and substance abuse. Regarding the years of study at the medical school, as well as sex and age differences, there were no significant differences between students.

Authors' contributions: Conception and design: DŽA, AD and VŠ; Acquisition, analysis and interpretation of data: DŽA, AD and VŠ; Drafting the article: VŠ, AD and DŽA; Revising it critically for important intellectual content: DŽA, LZS and KMA; Approved final version of the manuscript: DŽA, ŠV, AD, DŽA, LZS and KMA.

Conflict of interest: The authors declare that they have no conflict of interest.

\section{References}

1. Kessler RC, Berglund P, Demler O, Jin R, Koretz $\mathrm{D}$, Merikangas KR, et al. The epidemiology of major depressive disorder: Results from the National Comorbidity Survey Replication (NCS-R). JAMA. 2003;289(23):3095-105.

2. World Health Organization. Depression. Geneva (Switzerland): World Health Organization; 2018. [cited 2018 Mar 24]. Available from: http://www. who.int/mediacentre/factsheets/fs369/en/.

3. Kaplan JH, Sadock BJ. Clinical psychiatry manual [in Croatian]. Jastrebarsko: Naklada "Slap”; 1998.

4. World Health Organization. Depression: A global crisis, World Mental Health day. Geneva (Switzerland): World Health Organization; 2012. [cited 2018 Mar 24]. Available from: http://www.who. int/mental_health/management/depression/ wfmh_paper_depression_wmhd_2012.pdf.

5. World Health Organization. "Depression: let's talk" says WHO, as depression tops list of causes of ill health. Geneva (Switzerland): World Health Organization; 2017. [cited 2018 Mar 24]. Available from: http://www.who.int/mediacentre/news/releases/2017/world-health-day/en/.

6. Rotenstein LS, Ramos MA, Torre M, Segal JB, Peluso MJ, Guille C, et al. Prevalence of depres- sion, depressive symptoms, and suicidal ideation among medical students: A systematic review and meta-analysis. JAMA. 2016;316(21):2214-36.

7. Institute for public health of Canton Sarajevo. Study on the health status of the population, health conditions and health activities in Sarajevo in 2016 [in Bosnian]. Sarajevo (Bosnia And Herzegovina): Institute for public health of Canton Sarajevo; 2017.

8. Chen L, Wang L, Qiu XH, Yang XX, Qiao ZX, Yang YJ, et al. Depression among Chinese University students: Prevalence and socio-demographic correlates. PloS One. 2013;8(3):e58379.

9. Bayram N, Bilgel N. The prevalence and socio-demographic correlations of depression, anxiety and stress among a group of university students. Soc Psychiatry Psychiatr Epidemiol. 2008;43(8):667-72.

10. Bostanci M, Ozdel O, Oguzhanoglu NK, Ozdel L, Ergin A, Ergin N, et al. Depressive symptomatology among university students in Denizli, Turkey: prevalence and sociodemographic correlates. Croat Med J. 2005;46(1):96-100.

11. Sokratous S, Merkouris A, Middleton N, Karanikola $M$. The association between stressful life events and depressive symptoms among Cypriot university students: a cross-sectional descriptive correlational study. BMC Public Health. 2013;13:1121.

12. Beck AT, Steer AR, Brown KG. Beck Depression Inventory [in Croatian, Bosnian and Serbian], Jastrebarsko: Naklada "Slap"; 2011.

13. Richter P, Werner J, Heerlein A, Kraus A, Sauer H. On the validity of the Beck Depression Inventory. A review. Psychopathology. 1998;31(3):160-8.

14. Dogan O, Dogan S, Corapcioglu A, Celik G. The prevalence of depression in university students and its relation with some variables [in Turkish]. Journal of Cumhuriyet University Medical Faculty. 1994;16:148-51

15. Craft LL, Freund KM, Culpepper L, Perna FM. Intervention study of exercise for depressive symptoms in women. J Womens Health (Larchmt). 2007;16(10):1499-509.

16. Cohen S. Social relationships and health. Am Psychol. 2004;59(8):676-84.

17. Ammouri AA, Kaur H, Neuberger GB, Gajewski B, Choi WS. Correlates of exercise participation in adolescents. Public Health Nurs. 2007;24(2):11120.

18. Ghaedi L, Mohd Kosnin AB. Prevalence of depression among undergraduate students: Gender and age differences. International Journal of Psychological Research. 2014;7(2):38-50. 